\title{
Panorama de la arquitectura religiosa en el área metropolitana de Concepción, Chile (1960/90)
}

Panorama of religious architecture in the metropolitan area of Concepción, Chile (1960/90)

Luis Andrés Darmendrail Salvo · Archivo de Arquitectura Universidad del Bío-Bío (Concepción, Chile)

https://doi.org/10.17979/aarc.2015.4.0.5128

\section{RESUMEN}

Durante la década de 1960, se produjeron importantes transformaciones en la arquitectura de Concepción, Chile. El efecto de un terremoto y la puesta en marcha de un renovado Plan Regulador generaron cambios sustanciales en la manera de concebir la arquitectura local. Asimismo, la Iglesia Católica vivió procesos de cambio que repercutieron en su arquitectura. Concepción fue parte de esos cambios y en la totalidad de su área metropolitana se construyeron obras de arquitectura religiosa que trascendieron el paso del tiempo. Estas obras (que además repercutieron en los planteamientos de templos protestantes) trascendieron más allá de su función espiritual, en particular, teniendo un impacto urbano notorio, configurando manzanas y barrios y pasando a ser hitos importantes y apreciados en la ciudad.

\section{PALABRAS CLAVE}

Patrimonio, arquitectura moderna, arquitectura religiosa, Concepción, Chile.

\begin{abstract}
During the 1960's decade, the city of Concepción, Chile, went through several changes. The impact of an earthquake and a new Urban Plan determined substantial transformations in the way of perceive local architecture. At the same time, Catholic Church also went through important changes that were reflected on its architecture. Concepción was part of those transformations and examples of those buildings can be found on its entire metropolitan area. These pieces (that also influenced the architecture of protestant churches) transcended more than the spiritual aspects, rethinking the architecture, creating and configuring neighborhoods and public spaces and becoming important and appreciated landmarks in the city.
\end{abstract}

\section{KEYWORDS}

Heritage, Modern Architecture, Sacred Architecture, Concepción, Chile. 


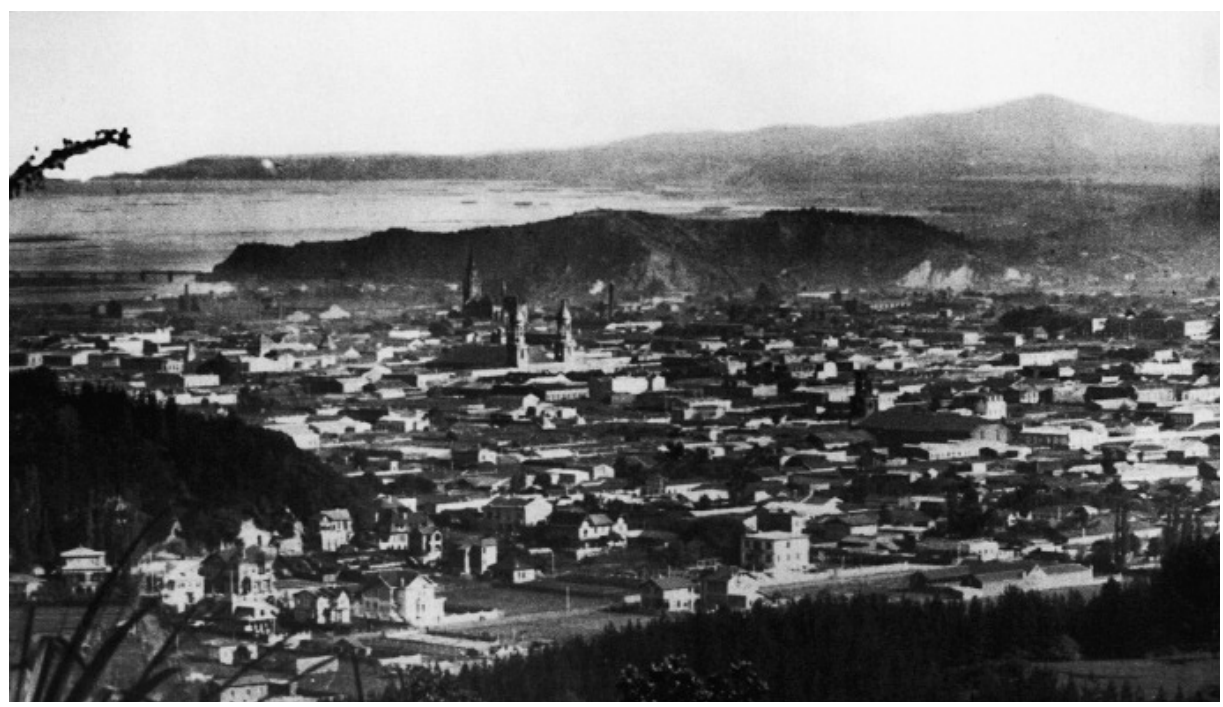

Fig. 01. Panorámica de Concepción, ca. 1920.

Ubicada en la zona centro-sur de Chile, la ciudad de Concepción fue fundada en 1550 y refundada en 1758 en un emplazamiento diferente al original, producto de un terremoto y posterior maremoto. La incidencia de las catástrofes sísmicas acentuó sucesivas transformaciones urbanas en sus 465 años de historia, que renovaron la urbe una y otra vez coincidiendo con cambios culturales, estilísticos, sociales y arquitectónicos. La arquitectura en Concepción ha dado cuenta de esos hechos.

Desde que el conquistador Pedro de Valdivia fundase la urbe en las playas del sector de Penco' en el siglo $\mathrm{XVI}$, las órdenes religiosas tuvieron cuadras dentro de una ciudad regular cuya trama siguió los lineamientos de un estructurado damero. En 1751, un terremoto y maremoto azotaron la ciudad, generando un éxodo en búsqueda de un nuevo sitio para Concepción, el cual se definió a algunos kilómetros del lugar fundacional ${ }^{2}$, esta vez, un valle rodeado por cerros y lagunas, el cual es su emplazamiento actual. La nueva Concepción se proyectó con trama urbana regular cuadriculada, y a cada una de las órdenes religiosas - como los Mercedarios, Dominicos, Trinitarias, entre otros- se les entregó una cuadrícula para que construyeran sus templos y conventos.

Magnificas iglesias se construyeron siguiendo patrones propios de la época, y a medida que los terremotos golpearon nuevamente a la ciudad, fueron reconstruidas sucesivas veces. Hasta las primeras décadas del siglo XX, la ciudad mantuvo una imagen sobria y de baja altura, siendo los templos religiosos las únicas construcciones que se escaparon a esa característica, con altas torres, excelsa escala y dominio en el perfil de esta ciudad, la cual dejaba atrás la imagen colonial heredada y mantenida por décadas (Fig. 01).

Las iglesias de antaño fueron proyectadas en su mayoría con planta de cruz y una marcada influencia neoclásica colonial. Posteriormente, muchos templos pasaron al academicismo francés, con recargadas propuestas adornadas con acabados trabajos artesanales de imaginería religiosa que hoy son parte de los tesoros religiosos de Concepción ${ }^{3}$.

A principios del siglo $\mathrm{XX}$, los templos pasaron por una fase ecléctica y adoptaron nuevos lenguajes como el neogótico o el neocolonial ${ }^{4}$. El panorama religioso era una conjunción de arcos de medio punto, rosetones, vitrales, ojivas, agujas y campanarios de escalas cada vez más excesivas, con trabajo decorativo notable, como la antigua catedral, que fue renovada incluyendo decoración afrancesada además de dos torres campanario $^{5}$ (Fig. 02).

En 1939, un nuevo terremoto barrió la arquitectura neoclásica presente en la ciudad. Tras el sismo, una vorágine arquitectónica renovada invadió las calles de Concepción, abarcando edificios residenciales, de ocio, 

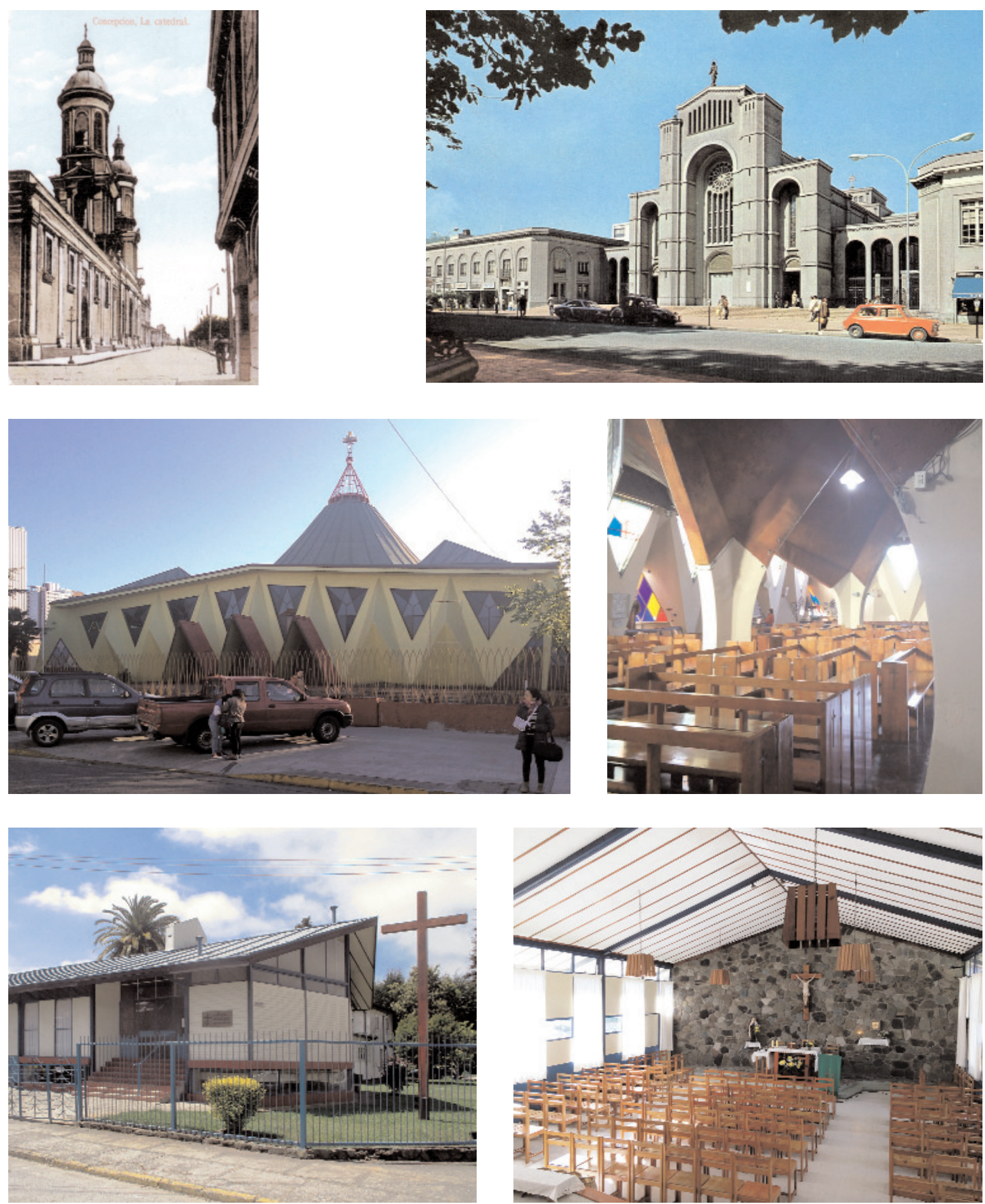
educacionales e institucionales, no así religiosos. Mientras la ciudad recibía una arquitectura sencilla, funcional y racionalista en cuanto a composición y volumen, la arquitectura religiosa mantuvo una imagen clásica, apelando a la restitución de cánones, como plantas con forma de cruz, distribución en tres naves y adopción de una arquitectura neorománica (incorporando, claro, las bondades del hormigón armado y los avances de la construcción), siendo exponentes la nueva catedral y la iglesia parroquial del Sagrario (Ramón Venegas, Carlos Casanueva y Fernando Urrejola, 1940/50) (Fig. 03) ${ }^{6}$.

La década de 1960 fue el momento culmine del ideario moderno en Concepción. Desde 1939, la ciudad se superó a sí misma en cuanto a vanguardia, exploración y adaptación de la idiosincrasia chilena en preceptos arquitectónicos forjados lejos de Chile. Altas torres residenciales comenzaron a aparecer en la ciudad y el color abrazó la arquitectura mediante mosaicos y cerámicas que dieron un nuevo ritmo a la urbe. Acentuando este proceso, un nuevo terremoto en 1960 terminó por derribar lo poco que había quedado del antiguo orden y coincidió con la puesta en marcha de un nuevo Plan Regulador Comunal, que germinó un ideario moderno con visión integral respecto al desarrollo de la ciudad como un sistema?.

Como si fuera poco, en medio de estos cambios, la Iglesia también pasó por transformaciones. Fueron los tiempos del Concilio Vaticano II, que determinó una nueva forma de concebir la práctica religiosa, acercando el credo a la comunidad y desplazando cánones que por cientos de años habían sido característicos de la Iglesia Católica. Este hecho quedó plasmado en la arquitectura religiosa, y Concepción, la ciudad en constante cambio, lo absorbió de forma gradual, con algunos casos particulares en los núcleos urbanos que componen su actual Área Metropolitana.

Tras el desplome de la decimonónica iglesia parroquial de San José, en 1964 los Capuchinos apostaron por una propuesta renovada a cargo de los arquitectos

Fig. 02. Jean Herbage, Catedral de la Santísima Concepción, Concepción (Chile), 1867. Torres y renovación de 1904 a cargo del arquitecto Eugène Joannon.

Fig. 03. Ramón Venegas, Carlos Casanueva y Fernando Urrejola, Catedral de la Santísima Concepción, Concepción (Chile), 1940/50. Fig. 04-05. Hernán Larraín y Jorge Riesco, iglesia parroquial de San José, Concepción (Chile), 1962/63.

Fig. 06-07. Osvaldo Cáceres, iglesia de la parroquia universitaria, Concepción (Chile), 1965.
Hernán Riesco y Jorge Larraín, quienes proyectaron una rupturista obra de planta cuadrada y muros perimetrales inclinados, en juegos de planos y vanos con ángulos marcados con una geometría rebuscada pero, al mismo tiempo, de fácil lectura (Fig. 04-05). Una expresión de pendientes intrincadas, planos inclinados $\mathrm{y}$ triangulados, además de una cubierta paraboloide con curvas y matizada con tragaluces que siguieron la geometría de la fachada. Su interior difiere totalmente a la concepción tradicional de una iglesia, y se dan diversas situaciones tanto en la distribución de los reclinatorios como por la misma posición del altar. Las concavidades generadas en los muros albergaron las imágenes de santos, y otras se utilizaron como bodegas. Se generó un exterior con patios y jardines y la iglesia se aisló de la idea de abarcar el máximo de superficie. El nuevo templo a pesar de su presentación, es liviano y se recorre perimetralmente a través de sus patios.

Esta idea de una presencia urbana directa fue utilizada también en otras propuestas como la Parroquia Universitaria, del arquitecto Osvaldo Cáceres (1965), proyecto asociado a la Universidad de Concepción y desarrollado como una sencilla estructura metálica cubierta de planchas de metal, madera y vidrio, usando muros de piedra para configurar zonas de importancia como el altar. La particularidad de la Parroquia Universitaria radica en la mixtura de usos. Utilizando una celosía, se cerraba el altar, y la iglesia se usaba como sala de espectáculos, aprovechando el desnivel del acceso como escenario. Bajo el desnivel, una sala multiusos dispuesta como zócalo fue sede de reuniones y actos (Fig. 06-07).

La inclusión del acero y del vidrio denotó la incidencia de estos materiales en la arquitectura religiosa, sacándolos de su rigidez —el hormigón y el metal se puede curvar o geometrizar-, mientras que la transparencia del vidrio denotó liviandad y austeridad en los templos. De a poco, el vidrio se introdujo de forma expresiva, como por ejemplo en el Templo Bautista de Luz Sobrino, abierto en 1963 (Fig. 08). Concebido como una gran basílica con un marcado acceso flanqueado por un muro cortina y coronado por un juego de losetas curvadas. Sus muros exhibieron leves pliegues y detalles diagonales y verticales que generaron un cierto ritmo acorde con mosaicos, cerámicas y volúmenes abstractos que decoraron su exterior, simbolizando un cambio también en las iglesias protestantes, a la par con la católica. 


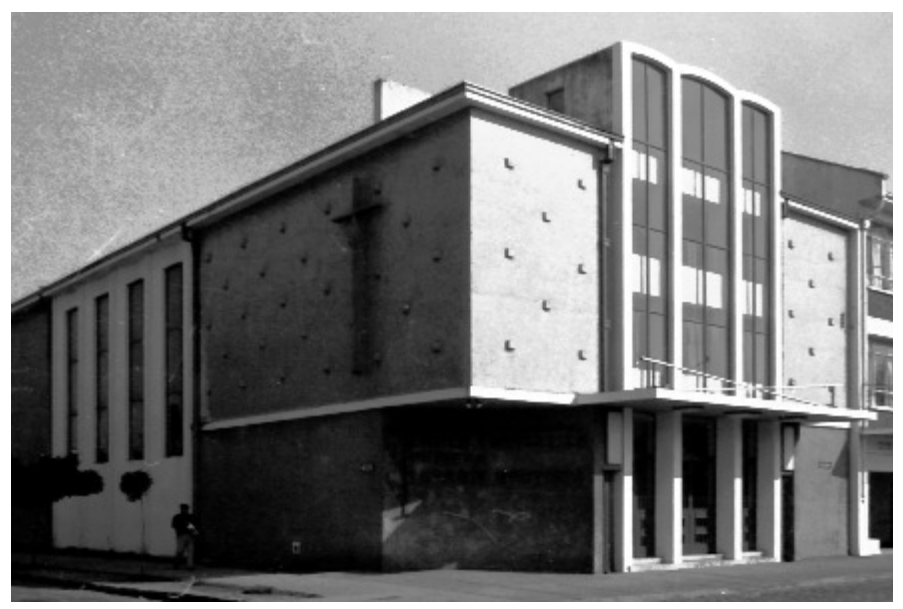

Fig. 08. Luz Sobrino, Templo Bautista, Concepción (Chile), 1965. Fig. 09. Santiago Roi y Ricardo Hempel, iglesia parroquial de Nuestra Señora del Carmen, Penco (Chile), 1965.

Fig. 11. Víctor Lobos, iglesia parroquial de Santa Cecilia, Talcahuano (Chile), 1965.
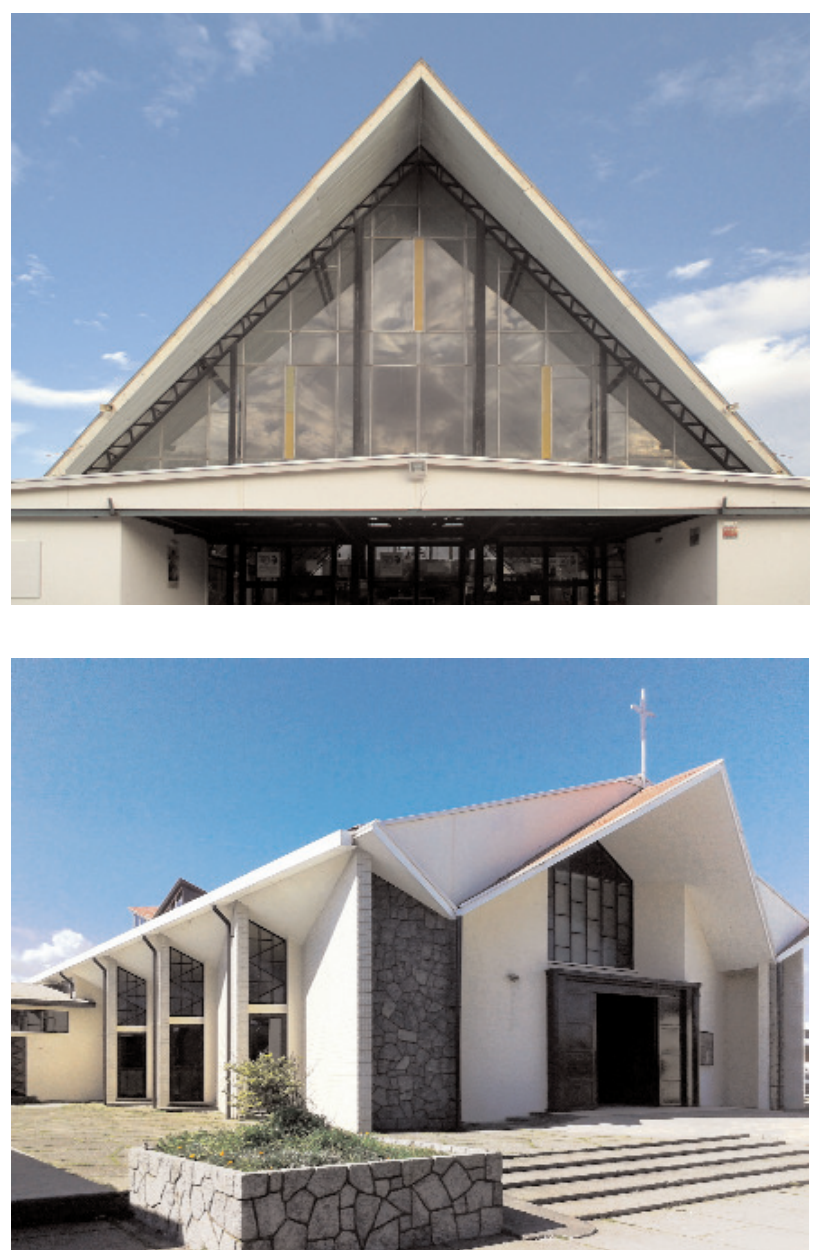
Fig. 10. Arturo Baeza y Talleres de Arquitectura PUCV, Santuario de la Virgen de la Candelaria, San Pedro de la Paz (Chile), 1966.

A medida que Concepción se modernizaba, la idea de una metrópolis intercomunal adquirió fuerza, y los núcleos urbanos adyacentes como Penco, Talcahuano y San Pedro también se vieron invadidos con propuestas renovadas. La iglesia de Nuestra Señora del Carmen, en Penco (1965), fue concebida como una sola nave estructurada en acero y revestida en vidrio, muy similar a la Parroquia Universitaria, pero con mayor transparencia y un muro cortina en el acceso (Fig. 09).

Si bien el acero y el vidrio se asociaron al hormigón en estas propuestas innovadoras, la madera también fue un material predominante. Tras el terremoto de 1960, alumnos de arquitectura de la Universidad Católica de Valparaíso desarrollaron templos en varias ciudades del sur, siendo el entonces barrio de San Pedro el beneficiado con la reconstrucción del Santuario de la Virgen de la Candelaria (Fig. 10). El proyecto estuvo a cargo del arquitecto Arturo Baeza y de nueve estudiantes de arquitectura. La nueva capilla llamó la atención por su plástica y geometría vanguardistas, además de la flexible utilización de la madera en estructura y revestimiento. Fue entregada en 1966 y refundada como parroquia. Lamentablemente esta iglesia no tuvo trabajos de preservación y cuidado de la madera, siendo afectada por el clima lluvioso, obligando a su demolición en 1987. El factor térmico y el confort fueron falencias de estas propuestas arquitectónicas. El uso de vidrio simple, de estructuras no revestidas, la carencia de aislantes y de estudios energéticos incidieron en complicaciones para fieles, al no

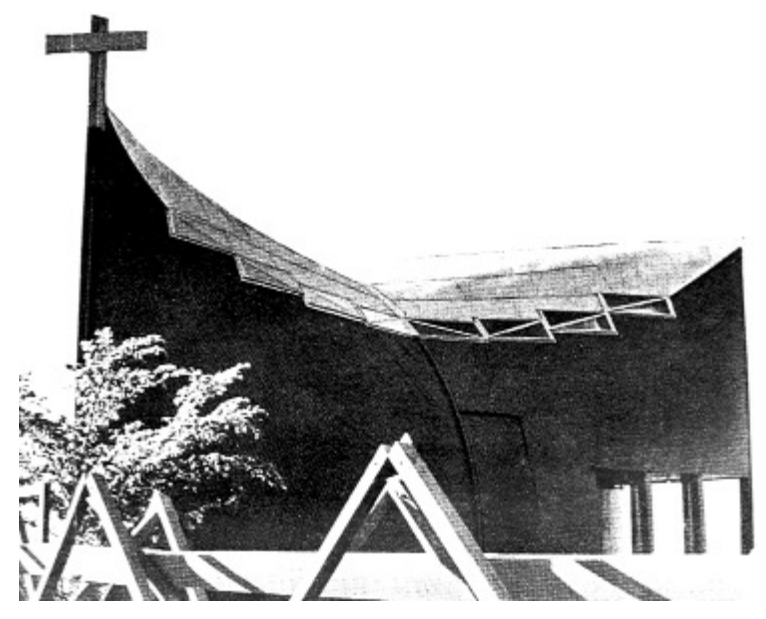

adaptar esas obras al inclemente clima de la zona y a la humedad existente.

El color fue explorado paulatinamente en obras como la iglesia parroquial de Santa Cecilia de 1965, obra del arquitecto Víctor Lobos (Fig. 11). Con una planta sencilla de una nave rodeada de planos plegados y una cubierta que sigue la composición, contó con un tratamiento de exteriores similar al de la iglesia parroquial de San José, brindando espacios de permanencia y jardines. Se incorporó un elemento vertical en el exterior que cumplió la función de cruz y campanario, revestido en cerámicas de colores al igual que el templo.

La fragmentación de la unidad de los templos fue una característica de estas propuestas que separaban funciones anexas como oficinas, secretarías, velatorios, etc. en recintos separados, formando conjuntos que en su totalidad tienen tanto valor como los templos en sí mismos, cualidad presente además en conjuntos comerciales y residenciales, en una ruptura de la concentración de las manzanas, estableciendo en su interior, vacíos, jardines y plazas como articuladores del espacio.

La década de 1970 fue una continuación de lo previamente expuesto y se destacaron dos proyectos. El primero en el puerto de Talcahuano. En 1975 se inauguró la nueva parroquia de San José, proyecto de los arquitectos Gabriela González, Ernesto Vilches y Pedro Tagle, quienes desarrollaron un enjambre de curvas y parábolas formando grandes arcadas cruzadas y entrelazadas, cuyos espacios intermedios formaron vanos en los que la luz penetra focalizada destacando el altar 

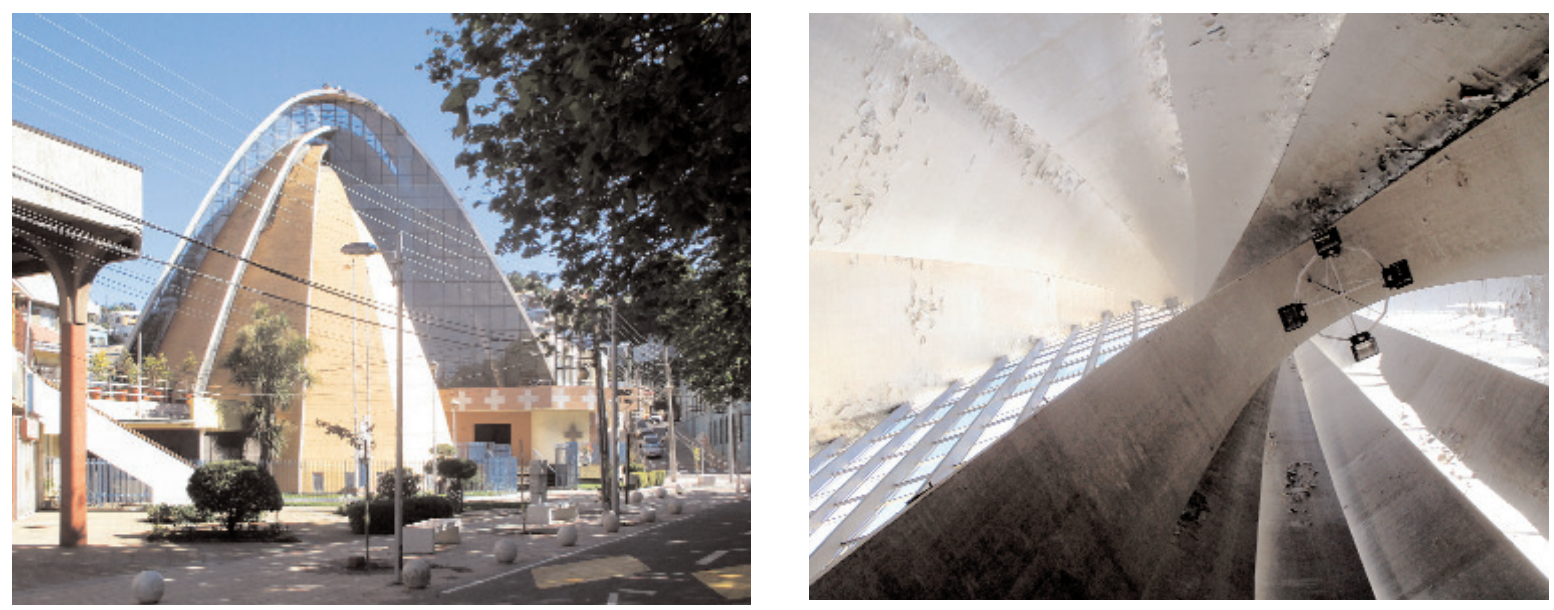

Fig. 12-13. Gabriela González, Ernesto Vilches y Pedro Tagle, iglesia parroquial de San José, Talcahuano (Chile), 1965.

Fig. 14. Roberto Goycoolea, iglesia parroquial de María Auxiliadora, Concepción (Chile), 1965.

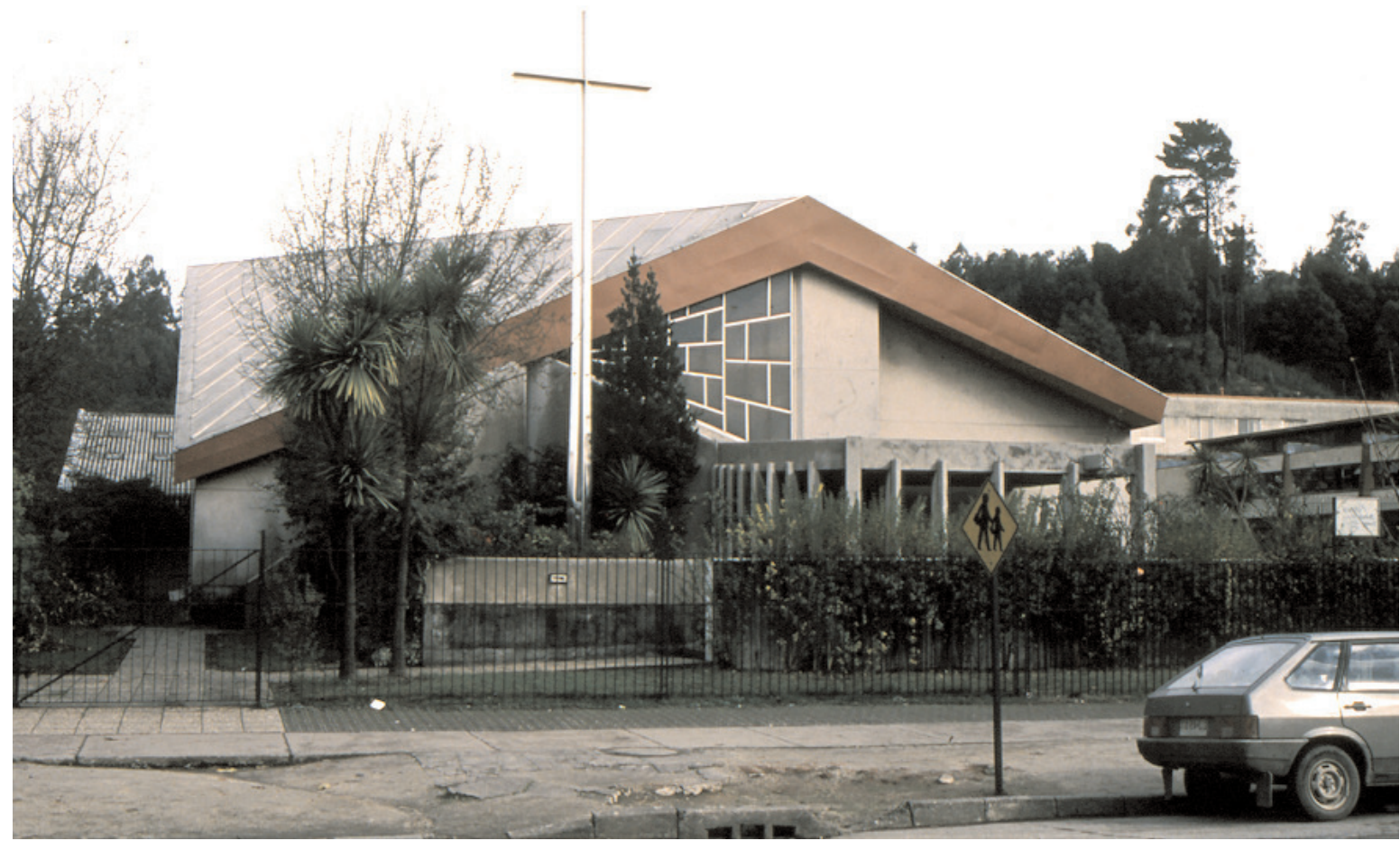


(Fig. 12-13). El desafío estructural presente fue cumplido y la iglesia simbolizó el progreso en la ciudad puerto, a pesar de las críticas recibidas respecto a su plástica y composición.

En 1977 se construyó en Concepción la iglesia parroquial de María Auxiliadora, obra de Roberto Goycoolea. Una sencilla obra en la que se jugó con planos inclinados y con el valor de la cubierta como configurador de espacios, además de poseer una plástica lúdica con un trompe l'oeil en fachada (Fig. 14). Hormigón, vidrio y madera combinados en un exacto equilibrio.

Las iglesias expuestas son fieles representantes de una transformación en la arquitectura y son un testimonio de que Concepción vivió una utopía moderna. Pinceladas de un desarrollo arquitectónico marcado por sueños que, conjugados con un espíritu progresista de la Iglesia, formaron parte de un esquema renovado de ciudad, en que el futuro se vislumbró a través de la genialidad y la belleza.

Hoy en día, cuando Concepción se proyecta como una urbe industrializada y en constante crecimiento, debemos reconocer el valor que la arquitectura moderna tiene en la ciudad, como símbolo de sus transformaciones, de su recuperación tras las catástrofes y como tesoros arquitectónicos con múltiples lecturas y dimensiones, más allá de lo espiritual: como patrimonio de todos nosotros.

\section{NOTAS}

(1) Concepción fue fundada en la zona costera, en la actual ciudad de Penco, el 5 de octubre de 1550.

(2) Jesuitas y Trinitarias fueron las órdenes principales de la ciudad, con amplias instalaciones, conventos y establecimientos educacionales. Los Jesuitas abrieron la primera universidad de la zona, y además, mantuvieron una estrecha relación con la población existente.

(3) Numerosas piezas aún se conservan a pesar de los terremotos y reconstrucciones. Desde Vírgenes elaboradas en España en el siglo XVI a imaginería del siglo XIX, como pinturas, retablos y mobiliario.

(4) En las primeras décadas del siglo XX se inauguraron los templos de San Ignacio y Sacramentino, e iglesias neogóticas de gran escala. Asimismo, la orden de los Escolapios hizo un colegio y un templo de características similares, alejándose de los aspectos neoclásicos.

(5) Concepción ha tenido cinco catedrales, marcadas por los terremotos. La comentada correspondió a la cuarta, iniciada a mediados del siglo XIX, renovada en 1915 y destruida en 1939 en el gran terremoto.

(6) La vertiente conservadora de la arquitectura en la ciudad se manifestó con fuerza en la década de 1950 con un revival de elementos clásicos y ornamentos. No sólo la catedral fue un ejemplo claro, sino también la iglesia parroquial de San Agustín (Jorge Velasco Urzúa, 1958).

(7) El Plan Regulador de 1960 fue obra de los arquitectos Emilio Duhart y Roberto Goycoolea. Se destacó por la estratificación de funciones dentro del centro de la ciudad, creando un ideario moderno de ciudad y anclado a un proyecto macro intercomunal que vislumbró la creación del Área Metropolitana de Concepción, englobando núcleos urbanos aledaños.

\section{BIBLIOGRAFÍA}

Archivo personal del arquitecto Osvaldo Cáceres.

Cáceres González, Osvaldo. 2006. La arquitectura de Chile independiente. Concepción: Universidad del Bío-Bío.

Cerda Brintrup, Gonzalo. 1994. «Arquitectura moderna en Concepción: 1939-1960», Arquitecturas del Sur 22:1-12.

Rivera, Angela. 1998. Monografia de la arquitectura de Gabriela González. Concepción: Universidad del Bío-Bío.

\section{PROCEDENCIA DE LAS ILUSTRACIONES}

Fig. 01, 03-07, 09 y 11-13. Archivo Luis Darmendrail Salvo.

Fig. 02. Archivo Armando Cartes Montory. Fig. 08 y 14. Archivo de Arquitectura Universidad del Bío-Bío.

Fig. 10. Auca 13 (1968). 